\section{CRITÉRIOS BÁSICOS PARA A DEMOCRACIA: É A RESPONSIVIDADE PARTE DE SEU CÍRCULO ÍNTIMO?}

\author{
BASIC CRITERIA FOR DEMOCRACY: IS \\ RESPONSIVENESS PART OF THE INNER CIRCLE?
}

Hans-Joachim Lauth

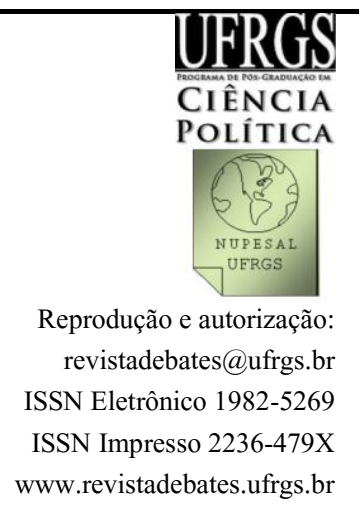

\begin{abstract}
Resumo
Responsividade, um principio básico da democracia, sua relevância e nossa compreensão desse conceito são examinados por duas razões. Em primeiro lugar, a qualidade da democracia e com isto a regressão da democracia estão frequentemente vinculadas a responsividade nos debates públicos. Em segundo lugar, levamos em consideração definições cruciais da democracia, as quais têm dado uma direção para a pesquisa sobre Democracia Comparada. Tais discussões, frequentemente têm ignorado que a qualidade da democracia também se revela via critério de responsabilidade. Quais, então, são os critérios necessários para resolver o conflito em termos de qualidade democrática? Em que medida o critério de responsividade é de limitada adequação em tornar as democracias acessíveis. Em que circunstancias pode a responsividade pode ser um critério adequado para determinar a qualidade da democracia? Um baixo grau de responsividade pode sempre ser indicativo de uma perda da qualidade democrática? São esses os objetivos deste artigo.
\end{abstract}

Palavras-Chave: Qualidade da Democracia; Responsividade.

\begin{abstract}
Responsiveness, a basic principle of democracy, its relevance as well as our understanding of it are examined for two reasons. Firstly, the quality of democracy and with it the regression of democracy are often linked to responsiveness in public debates. Secondly, we are considering crucial definitions of democracy, which have given direction to research into Comparative Democracy. This discussions have often ignored that the quality of democracy also reveals itself via the criterion for responsibility. Which are then the necessary criteria in order to solve the conflict with in terms of democratic quality? Moreover, how far the responsiveness criterion is of limited suitability in making democratic quality accessible. Put in another way, under what circumstances can responsiveness (or its related procedures) be a suitable criterion for determining the quality of a democracy? Does a lower degree of responsiveness always indicate a loss of democratic quality? These are the objectives of this article.
\end{abstract}

Keywords: Democracy Quality; Responsiveness. 


\section{Introdução: sobre a relevância de critérios sobre a qualidade ${ }^{1}$}

O debate atual sobre o desenvolvimento democrático se caracteriza por um ceticismo que surge mais da evidente insatisfação com o estado atual da democracia do que do próprio estagnante número de democracias. Empiricamente, a insatisfação se manifesta em pesquisas a respeito do desempenho de uma dada instituição da democracia. A falta de confiança é obvia tanto nas novas como nas democracias estabelecidas. Esta insatisfação, ou melhor, esta avaliação cética se encontra também em estudos acadêmicos. Portanto, muitas novas democracias são julgadas como defeituosas ou deficientes como freqüentemente e de forma reconhecida mostram insuficiências em seu funcionamento democrático. De qualquer forma, as democracias estabelecidas também têm se tornado objeto de crítica como tem demonstrado o debate sobre Pós-democracia (CROUCH, 2004). Em todos os casos mencionados aqui o foco de interesse é a qualidade da democracia. Ela tem se constituído em um topos central da pesquisa atual sobre a democracia.

Determinar a qualidade da democracia não significa mais do que esclarecer como esta deve ser mensurada. Qualquer que seja a medida escolhida, seja uma definição mínima ou exigente - define sobre o número de democracias, bem como sobre a sua suposta qualidade. Em virtude dessa relevância, é obvio que o ponto de referencia em si, deve ser objeto de uma decisão cuidadosa. Há um crescente corpo de estudos que trabalha cuidadosamente desta questão básica. Como exemplo, dois volumes de trabalhos selecionados merecem menção especial: The Quality of Democracy (O'DONNELL et. al., 2004) e Assessing the Quality of Democracy (DIAMOND e MORLINO, 2005), os quais retomam a discussão do anterior. Na introdução, Diamond e Morlino tentam compilar uma síntese de distintas visões sobre a democracia. Eles identificam oito dimensões, sendo elas: respeito à legalidade, accountability vertical e horizontal, participação, competência, responsividade, liberdade e igualdade. Estas dimensões claramente foram além da proposta pioneira de Robert Dahl de 1971 (Poliarquia), quem com competência e participação trouxe ao debate duas dimensões, embora a proposição deles seja limitada. Se estudarmos a proposta de Diamond e Morlino mais de perto, nota-se imediatamente que mesmo o termo "dimensão" permanece nebuloso. Assim as dimensões individuais variam quanto ao seu grau de abstração (e, com isso, em seu alcance). Por exemplo, a "liberdade" poderia também ser entendida como um rótulo para "competência" e "accountability vertical". Ao mesmo tempo, nem todas as dimensões são concebidas separadamente umas das outras e, portanto se sobrepõem entre si. Finalmente, elas ou são ou substancializadas em diferentes graus ou permanecem vagas. Embora esta proposta enriqueça a discussão, ainda fica muito por esclarecer. Esta tarefa é necessária não só para medir a

\footnotetext{
${ }^{1}$ Tradução livre da Equipe do Nupesal.
} 
qualidade da democracia, mas também para identificar possíveis regressões ou incrementos de sua qualidade.

\section{A Qualidade da Democracia - solução metódica, estratégia e descobertas}

Com o objetivo de definir uma síntese do debate democrático de maneira precisa, é essencial reconstruir sistematicamente o termo democracia usando regras claras (LAUTH, 2004). Neste sentido o seguinte pressuposto básico é proposto: a democracia é um construto social. Idéias centrais são introduzidas e agregadas pelo debate público e definidas com mais precisão no debate acadêmico. $\mathrm{O}$ debate acadêmico, por sua parte, se orienta ao mesmo tempo por linhas de desenvolvimento histórico em referências à filosofia política, por um lado, e aos processos reais-históricos, por outro. Apesar das grandes diferenças em seu desenho concreto, um núcleo normativo está subjacente a todas essas considerações; este núcleo se refere à idéia da soberania popular. Quanto mais precisas as idéias sobre a democracia tornem-se, mais intensamente será interpretado e complementado o núcleo normativo, assim as sugestões variam de acordo.

Para uma perspectiva sistemática em torno da Teoria da Democracia, se sugerem que as seguintes regras pragmáticas para determinar a qualidade da democracia:

(1) Abstração: Aqui as bases normativas são reconstruídas, na medida do possível, em suas formas abstratas básicas a partir das concepções atuais sobre democracia.

(2) Modularização: Neste segundo nível os componentes centrais ou módulos da democracia são identificados em um nível mais baixo de abstração, situados no nível do desenho institucional. Nesta abordagem, as instituições relevantes para a democracia são citadas como exemplos.

(3) Construção: Combina a abstração e modularização. Ao fazê-lo, as seguintes regras deveriam ser observadas:

a) Coerência (ou validade do conteúdo). Os componentes institucionais devem corresponder às bases normativas do nível abstrato.

b) Parcimônia. Para limitar a divergência no nível de construção e para possibilitar a conexão com tantas variantes de democracia quanto possível, só devem ser considerados os elementos necessários.

c) Equivalentes funcionais deveriam ser identificados e integrados dentro de um único componente. 
Em outras palavras, devemos esclarecer quais formas institucionais são relevantes na realização das bases normativas, evitando um preconceito institucional.

(4) Devemos, além disso, diferenciar entre os elementos inerentes à democracia e aqueles que constituem fatores necessários e promocionais.

a) Fatores necessários (BRENNAM, 2003): estes são os fatores que, sem ser uma característica democrática especificamente, representam uma condição necessária para a qualidade da democracia (por exemplo, o Estado). Aqui, em princípio, a relação de causalidade estrita é relevante - se carece da condição necessária, a qualidade da democracia não pode existir. Da mesma forma que nas ciências sociais empíricas, nos defrontamos com resultados graduais; uma relação de causalidade análoga poderia ser que quanto mais frágil se dê a condição necessária, mais baixa a qualidade da democracia. Manter esta relação em mente não significa que a inter-relação inversa deva existir. A existência de um fator necessário (como o Estado) não implica que a democracia também esteja presente.

b) fatores obstrutivos e promocionais: aqui se assume hipoteticamente que a existência de fatores promocionais e obstrutivos (por exemplo, o grau de desenvolvimento sócioeconômico) melhora ou piora a qualidade da democracia. Não existe nenhuma correlação lógica estrita: a qualidade da democracia só pode ser parcialmente determinada pela extensão dos fatores promocionais. Assim, uma democracia de alta qualidade é possível inclusive com um grau médio de desenvolvimento sócio-econômico (como, por exemplo, Costa Rica e Uruguai), embora este caso seja mais uma exceção, ou que com um nível de desenvolvimento sócio-econômico alto, a qualidade da democracia possa ser baixa (República de Weimar). Por esta razão, o estudo dos fatores promocionais e obstrutivos tende a confirmar a hipótese sobre a estabilidade e o dinamismo da qualidade da democracia.

c) Fatores suficientemente obstrutivos: aqui se assume hipoteticamente que a existência de fatores obstrutivos pioram a qualidade da democracia. Inicialmente as relações são similares àquelas em $4 \mathrm{~b}$. Contudo, no caso de uma forte presença de fatores obstrutivos (por exemplo, quando a corrupção se converte em uma instituição informal), estes podem constituir uma precondição suficiente para enfraquecimento da qualidade democrática. Neste ponto deveríamos reiterar as pré-condições sócio-econômicas necessárias para a democracia, as quais desde os tempos de Lipset (1959) foram sujeitas a um forte debate (MUNO, 2001). Embora, com certeza, quando é exagerado estabelecer um estado de bem-estar integral como pré-requisito para uma alta qualidade da democracia, a falta de padrões sociais mínimos 
(educação, renda, emprego) leva a limitações para a participação no processo político ${ }^{2}$. Neste sentido, os baixos níveis de desenvolvimento social devem constituir fatores suficientemente obstrutivos, ou formulado de outra forma, os padrões sociais mínimos são condições necessárias para a extensão da qualidade democrática.

As claras separações analíticas não deveriam esconder o fato de que as relações empírica são, às vezes, mais complexas. Assim, um alto grau de desenvolvimento sócioeconômico constitui inicialmente um fator promocional. Entretanto, a partir de certo nível de baixo desenvolvimento, isto também pode ser interpretado como um fator obstrutivo. Finalmente, pode ser percebido, inclusive como uma condição necessária, se no nível de desenvolvimento baixo a mera sobrevivência não é assegurada. Esta variável, o grau de desenvolvimento sócio-econômico, se transforma de acordo com o grau de sua realização alcançado, em uma condição necessária, obstrutiva ou promocional.

(5) Evasão do estiramento conceitual (SARTORI, 1970). Até agora as considerações apresentadas aqui, mostram que para determinar a qualidade de uma democracia não só se deve incluir uma definição da democracia (como nos pontos 1 ao 3 abordados anteriormente), mas também tem que ser levadas em conta todo os fatores (como no ponto 4) que afetem o funcionamento da democracia. Desta forma, os fatores necessários e suficientes tem de ser incluídos na análise. Devido ao aumento de complexidade que isto implica, é importante refletir exaustivamente sobre todas estas relações, com a finalidade de evitar o alargamento conceitual, no qual fatores condicionais também são incluídos dentro do conceito de democracia.

No que diz respeito à determinação da qualidade da democracia, a que resultados chegamos quando analisamos criticamente a pesquisa empírica atual sobre a democracia (O'DONNELL, VARGAS CULLEL, IAZZETTA, 2004; DIAMOND, 2005; MERKEL et. al., 2003; LAUTH 2004; SCHMIDT 2006; BÜHLMANN et. al. 2008) por meio das regras discutidas anteriormente ${ }^{3}$ ?

No nível de dimensões abstratas se situam proeminentemente dois termos - os de liberdade e igualdade - para ser mais preciso, liberdade política individual e igualdade política individual. Nenhuma concepção relevante da democracia é suficiente sem referência a estas duas dimensões. Quando ambos os princípios básicos são tomados a sério, é lógico considerar

\footnotetext{
${ }^{2}$ Nenhuma norma geral se pode atribuir a padrões sociais mínimos, já que estes podem variar dependendo do contexto específico e em termos de sua composição. No entanto, o grau de educação geral é uma aproximação útil.

${ }^{3}$ Isto não pode ser desenvolvido dentro do marco deste ensaio. Para uma discussão mais completa, conferir Lauth (2004).
} 
a idéia de controle político e legal. Consequentemente, a noção de democracia é entendida como uma forma limitada de governo. A democracia encontra seus limites nas garantias de liberdade e igualdade individual. A maioria não tem permissão de dispor livremente dos direitos básicos da minoria. A compreensão da liberdade interrompe a liberdade do indivíduo em seus limites, ou seja, quando viola a liberdade dos outros. Definir qual controle deveria existir neste nível é essencial, bem como serve para orientar como se determinam os princípios institucionais básicos. Aqui, o controle opera em um nível político e legal. No nível legal, os princípios básicos do respeito à legalidade já foram estabelecidos neste nível de abstração; são, portanto, definidos totalmente no nível institucional. Para que um emprego adequado do controle legal possa ser possível, as possibilidades de controle político são essenciais; sendo considerado inclusive como prioritário (SCHMITTER, 2005). Entretanto, deve-se levar em consideração que o controle político encontra não só seus limites, mas também sua arma mais potente dentro do respeito à legalidade. Esta curta reflexão salienta três dimensões da democracia: liberdade política, igualdade política e controle político e judicial.

Neste nível de abstração, dois princípios adicionais básicos podem ser distinguidos sobre estas dimensões:

(1) Se a democracia está baseada na soberania popular, no sentido de uma forma coletiva de autogoverno individual, então as ações do governo fazem referência intrinsecamente às preferências dos participantes; esta referência encontra sua expressão na noção de responsividade. De acordo com isto, as decisões democráticas devem levar em conta as preferências de todos os cidadãos.

(2) Se a democracia é uma forma de governo limitada, que encontra sua justificativa em manter seus próprios princípios básicos e características centrais, então governar está alinhado ao princípio de responsabilidade. Por esta razão, as decisões democráticas devem refletir perspectivas de longo prazo e proteger seu próprio princípio básico (o dos direitos e liberdades civis). Responsividade e responsabilidade são dois princípios básicos que devem ser garantidos através do caráter institucional da democracia.

As dimensões e princípios da democracia encontram sua expressão plena nas formas institucionais. Aqui, o mínimo institucional se orienta para as garantias institucionais (DAHL, 1971), as quais incluem as leis eleitorais, como também a liberdade de organização e comunicação. Esta lista se estende através da característica de "um governo efetivo". O processo democrático não culmina com a formulação de decisões, mas com sua aplicação. A responsividade em relação às preferências do demos deve ser expressa no resultado do sistema político (SCHARPF, 1970; BENZ, 2003). Pela implementação de decisões políticas, 
entretanto, devemos dar atenção apropriada aos objetivos da ação política ${ }^{4}$. Quanto menores sejam estas, mais fortemente a habilidade de uma democracia dar forma e tomar decisões e, como ela, a sua qualidade, é comprometida. Com isto, desenvolve-se o argumento a partir dos qual a globalização e a dívida podem ser vistas como debilitadoras da qualidade democrática. Contudo, os input como os output, da mesma forma que a dimensão de controle requerem salvaguardas institucionais, as quais se encontram no respeito à legalidade e dentro os mecanismos de accountability politicamente ajustados. Esta divisão segue a separação sistemática entre o controle político e legal (LAUTH, 2004). De acordo com estas considerações, seis instituições podem ser tomadas em conta, cada uma representando um complexo mosaico institucional.

- Legislação eleitoral ativa e passiva (universal, livre, igual e secreta);

- Liberdade de organização;

- Liberdade de comunicação;

- Governo efetivo;

- Respeito à legalidade;

- Mecanismos (políticos) de accountability.

Outra possibilidade é mostrada na Tabela 1, a qual combina seis instituições em cinco (LAUTH, 2004).

\footnotetext{
${ }^{4}$ Deve-se notar que enviesar o conteúdo do resultado com a finalidade de determinar a qualidade da democracia - enquanto que melhor a situação econômica, mais alta a qualidade da democracia - não é factível. O ponto de referência são as preferências dos cidadãos. No entanto, só vale a pena notar uma exceção. Todas essas decisões que afetam negativamente o funcionamento da democracia em si, como também sua implementação, serão incluídas para determinar de forma negativa a qualidade da democracia.
} 
Tabela 1 - Matriz da democracia

\begin{tabular}{|c|c|c|c|}
\hline $\begin{array}{l}\text { Dimensões } \\
\text { Instituições }\end{array}$ & Liberdade & Igualdade & Controle \\
\hline \multirow{2}{*}{$\begin{array}{l}\text { Procedimentos de } \\
\text { decisão }\end{array}$} & $\begin{array}{l}\text { Eleições livres e } \\
\text { referendos }\end{array}$ & $\begin{array}{c}\text { Oportunidade de } \\
\text { participação igualitária, } \\
\text { igualdade de votos }\end{array}$ & $\begin{array}{l}\text { Controle exercido pela } \\
\text { junta independente de } \\
\text { revisão eleitoral }\end{array}$ \\
\hline & $1 / 1$ & 06 & $1 / 3$ \\
\hline \multirow{2}{*}{$\begin{array}{l}\text { Regulação da esfera } \\
\text { intermediaria }\end{array}$} & $\begin{array}{l}\text { Liberdade de } \\
\text { organização }\end{array}$ & $\begin{array}{c}\text { Direitos de organização } \\
\text { igualitários }\end{array}$ & $\begin{array}{c}\text { Controle por parte dos } \\
\text { partidos e da sociedade } \\
\text { civil }\end{array}$ \\
\hline & $2 / 1$ & $2 / 2$ & $2 / 3$ \\
\hline \multirow[t]{2}{*}{$\begin{array}{l}\text { Comunicação } \\
\text { pública }\end{array}$} & $\begin{array}{l}\text { Liberdade de } \\
\text { comunicação }\end{array}$ & $\begin{array}{c}\text { Igualdade de } \\
\text { oportunidades de } \\
\text { participar }\end{array}$ & $\begin{array}{l}\text { Controle por parte da } \\
\text { mídia (jornalismo } \\
\text { independente) }\end{array}$ \\
\hline & $3 / 1$ & $3 / 2$ & $3 / 3$ \\
\hline \multirow[t]{2}{*}{ Garantia de direitos } & $\begin{array}{l}\text { Livre acesso aos } \\
\text { tribunais }\end{array}$ & $\begin{array}{l}\text { Igualdade de direitos e } \\
\text { tratamento nos tribunais }\end{array}$ & $\begin{array}{c}\text { Efetividade de uma } \\
\text { ordem judicial da corte } \\
\text { suprema }\end{array}$ \\
\hline & $4 / 1$ & $4 / 2$ & $4 / 3$ \\
\hline \multirow[t]{2}{*}{$\begin{array}{l}\text { Estabelecimento e } \\
\text { execução das regras }\end{array}$} & $\begin{array}{c}\text { Governo efetivo } \\
\text { (Parlamento, } \\
\text { administração racional) }\end{array}$ & $\begin{array}{c}\text { Tratamento igualitário } \\
\text { por parte do Parlamento } \\
\text { e da Administração }\end{array}$ & $\begin{array}{l}\text { Separação de poderes } \\
\text { (oposição parlamentar, } \\
\text { segunda câmara, divisão } \\
\text { de auditoria) etc. }\end{array}$ \\
\hline & $5 / 1$ & $5 / 2$ & $5 / 3$ \\
\hline
\end{tabular}

Fonte: Elaboração própria.

Nesta etapa, pode ser discutido um entendimento mais preciso das instituições designadas, na qual as diferenças entre os distintos enfoques poderiam se tornar mais evidentes. Entretanto, as regras discutidas previamente deveriam ao menos levar à redução da margem de possíveis resultados. $\mathrm{Na}$ discussão sobre instituições necessárias, se referir a equivalentes funcionais poderia servir de guia. A pergunta central é: quais instituições podem possibilitar o funcionamento das dimensões e princípios centrais? Estas permanecem constantes, de fato, enquanto variam o caráter das instituições, também é possível incluir instituições informais. Assim, a legislação eleitoral não é uma referência para a representação, mas também inclui procedimentos de democracia direta. A combinação de relações que se mostra como a mais produtiva para a transferência de preferências, tem que ser escolhida em 
casos concretos. O mesmo pode ser dito sobre a legislação eleitoral, localizada no espectro entre a votação proporcional e majoritária.

Reconsiderar as regras de análise nos leva ao quarto e quinto pontos de verificação, os quais se referem às condições promocionais, suficientes, obstrutivas e necessárias. Como o esclarecimento do significado dos fatores obstrutivos e promocionais requerem um estudo empírico, as condições necessárias deveriam ser mencionadas neste ponto. A estas pertence o respeito à legalidade, conforme mencionado e, sem o qual todos os regimes democráticos mostrariam um enfraquecimento de sua qualidade. Entretanto, a transparência também deve ser mencionada, já que sem esta, nenhum processo político democrático pode funcionar. Isto começa quando a formação de preferências abrange a legislação de organização e comunicação e inclui controle. Inversamente, o enfraquecimento dos processos democráticos através de um alto grau de corrupção e práticas informais similares são uma condição suficiente para reduzir a qualidade da democracia.

A respeito de Diamond e Morlino, ainda fica por esclarecer onde exatamente se situa a participação. Outros tipos de regimes políticos também têm formas de participação. Portanto, a participação propriamente dita não é uma característica da democracia em geral, mas um modo bem específico de participação democrática. Isto é mostrado na compreensão das dimensões e princípios a partir do conjunto específico de instituições democráticas, as quais por sua vez, estão todas dirigidas para a participação. Por esta razão, a participação pode ser entendida como a forma essencial que permite as características democráticas, possibilitando sua integração. Ao fim de nossa reflexão as regras pragmáticas de análises sugeridas, demonstram sua capacidade de sistematizar o conceito de Diamond e Morlino (2005). 
Diagrama 1 - Qualidade da Democracia: elementos básicos

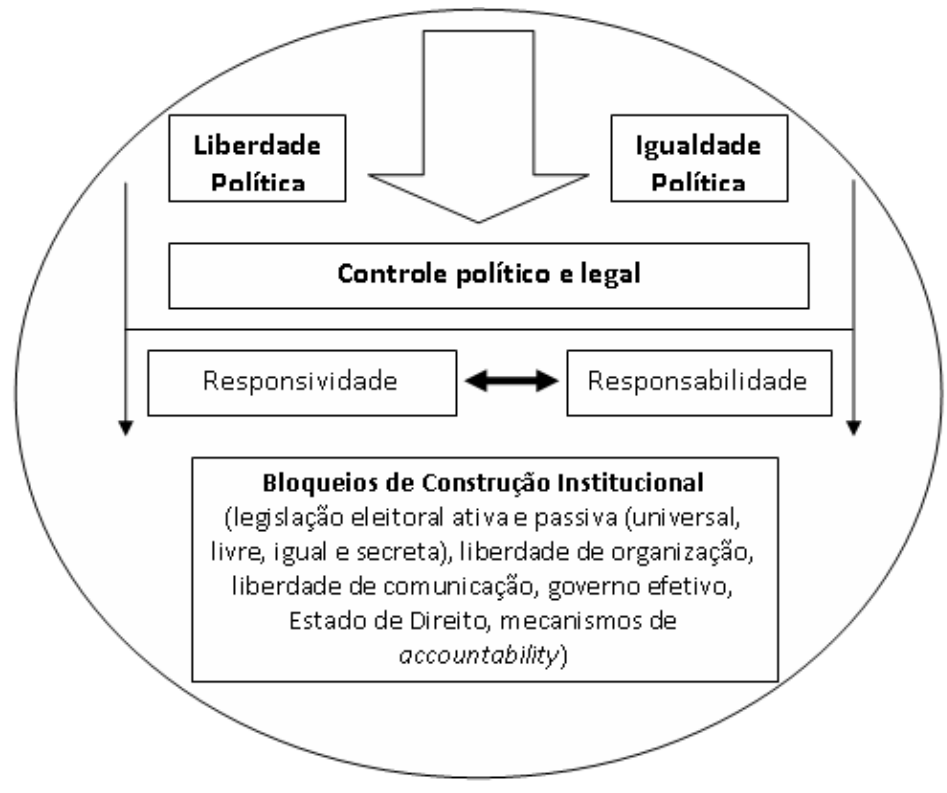

Fonte: Elaboração própria.

Considerando todas as propostas acerca das dimensões, a democracia é melhor entendida com base nas três dimensões da liberdade política, igualdade política, e controle político e judicial. Elaborar uma lista de todas as características relevantes de uma democracia não implica que o nível mais alto de qualidade democrática seja alcançado quando todas são exaustivamente desenvolvidas. Pelo contrário, devem ser considerados os possíveis trade-offs em todos os níveis. Estes são motivados significativamente pela relação tensa entre dimensões localizadas no nível de abstração mais elevado.

A área de conflito mais conhecida se refere à tensão entre a liberdade e a igualdade, à qual tem dado lugar a um sério debate ideológico e filosófico (HELD, 1987; REISINGER, 1997). A perda de equilíbrio entre ambas dimensões da democracia a favor da igualdade é vista por Tocqueville como uma ameaça central à liberdade. A liberdade e a igualdade entram em um conflito mais profundo quanto mais fortes as demandas substanciais estão conectadas com a noção de igualdade. A crítica das Teorias da Democracia, social, participativa e feminista, de sua variante liberal, oferece uma perspectiva de múltiplas facetas. De acordo com estas, a realização das opções de participação (como uma expressão dos direitos de liberdade), requerem primeiro a criação de igualdade de oportunidades através de transferências materiais ou sistema de cotas. No entanto, na perspectiva do liberalismo clássico, são precisamente tais mecanismos os que diminuem a execução ilimitada de direitos 
humanos liberais ${ }^{5}$. Não obstante, mesmo ao renunciar a uma conexão material de direitos formais de liberdade com o propósito de permitir o domínio de valores liberais, falha em aliviar a tensão, como Zippellius (1991, p. 325) afirma: “On the other hand, a certain measure of equality also in real development opportunities, is indispensable, in order to maintain freedom as universal freedom over time". No debate que em torno de ambas as diretivas, é menos esta concepção que é controversa, do que a definição de "certo grau". Alguns critérios de orientação já foram abordados sobre a discussão relacionada com as pré-condições sociais necessárias para a democracia.

Também existe tensão entre dimensões de liberdade e controle. A difusão de mecanismos de controle limita os domínios da liberdade individual e/ou coletiva, com o propósito de realizar uma juridificação burocrática, a qual regule e restrinja o espaço para a organização e a ação política. Ao contrário, qualquer extensão da dimensão de liberdade ocorre às custas das possibilidades de controle; isso se demonstra na possibilidade decrescente de accountability horizontal. A tensão faz eco nos imperativos divergentes de responsividade e responsabilidade. No nível abstrato, esta tensão é expressa na limitação da regra da maioria política através do respeito à legalidade e a legislação constitucional.

Ao mesmo tempo, com suas complexas regras procedimentais, um governo democrático oferece uma solução ao conflito entre a liberdade e a limitação do poder. Este conflito, entretanto, sempre permanece latente e se manifesta com mais força quando muda o equilíbrio entre os pólos. Mesmo se o controle da democracia operar de acordo com os princípios do respeito à legalidade, a formulação da legislação constitucional dos direitos relacionados segue tendo margem suficiente para tomar as decisões políticas, e deveria seguir sendo possível a livre autodeterminação. Por sua vez, a liberdade ilimitada tende à tirania da maioria (ou dos governantes) quando falha em observar as limitações estabelecidas pelo respeito à legalidade. Desta forma, a democracia se expressa dentro de ambas as dimensões, não obstante esta se distorça quando alguma começa a predominar. Mesmo quando a democracia se expressa apropriadamente dentro do equilíbrio entre liberdade e controle, fica por definir qual é o grau correto da especificidade de cada dimensão ${ }^{6}$.

Que potencial de tensão se poderia dizer que existe entre igualdade e controle? Inclusive a implementação estrita do princípio de igualdade pode reduzir a efetividade da dimensão de controle, se ao fazê-lo, se combina uma participação permanente e geral do

\footnotetext{
${ }^{5}$ Correspondentemente, Habermas (1996, p. 304) afirma: "the 'wrong' classifications (to reduce gender discrimination - the author) lead namely to normalizing readjustments to one's life, turning the intended compensation into renewed discrimination, turning bailment of freedom into loss of freedom".

${ }^{6}$ Ao longo do desenvolvimento histórico da democracia, pode ser observado o crescimento da relevância da dimensão de controle, no qual de fato tem restringido os domínios de liberdade e se expressa mais claramente no compromisso do soberano de direito constitucional.
} 
demos, sem delegar órgãos específicos. Uma organização eficiente dos mecanismos de controle, os quais em particular exigem a inclusão de instituições funcionalmente especializadas, reduz a igualdade de participação em assuntos relacionados com o controle. A diferenciação funcional tende a concentrar o controle nas mãos de elites altamente qualificadas. De acordo com isto, Alexy (1998) afirma:

That only constitutional court jurisdiction represents real control, does not mean that the solution to the issue of control has been found. The disadvantages of constitutional court jurisdiction could be greater than the advantages in terms of the control of the democratic process that it brings. The disadvantages lie within the dangers of constitutional court paternalism (Habermas), with could entail the transition from parliament legislative state to one base on the jurisdiction of the constitutional court (Böckenförde). (ALEXY, 1998, p. 244).

Com a finalidade de evitar uma forma de democracia elitista nesta dimensão, se requer um alto nível de transparência nos processos políticos e cooperação por parte dos cidadãos através de informação e comunicação.

O efeito de uma dimensão de controle dominante sobre a igualdade resulta óbvio se uma corte constitucional, assumindo tal grau de desenvolvimento da autoridade, tende ao ideal de governo dos filósofos, como o concebeu Platão (HÖFFE, 1999) ${ }^{7}$. Dentro da concepção de governo da elite implica que a igualdade de participação política é inerente dentro de uma democracia efetivamente minada. Controle - especialmente quando se baseia na autoridade para exercer a autoridade - requer uma forte medida de moderação, limitando a atividade da corte constitucional a aspectos de norma constitucional, o que deixa aberto os temas de política constitucional, como propõe Höffe (1999). A dificuldade envolvida em identificar e respeitar este limite em casos individuais aponta para um mais amplo debate sobre a limitação inerente à democracia.

Estas considerações sobre o potencial para a tensão entre as três dimensões podem ser resumidas da seguinte forma: em princípio, uma democracia "ótima" ou "perfeita" não se pode basear na realização completa de todas as três dimensões; mas, esta se expressa em uma execução apropriada e gradual, mantendo o equilíbrio entre elas. Ficar preso tanto aos seus limites quanto exercê-los é problemático.

Finalmente, definir o que deveria ser este equilíbrio é a expressão de um contínuo debate dentro da sociedade e deve permanecer dependente das situações históricas. Em sua busca pelo equilíbrio entre as três dimensões, a democracia, ou melhor seus cidadãos (vistos

\footnotetext{
${ }^{7}$ De acordo com Alexy (1998, p. 224) este perigo só pode desaparecer por meio de "successful embedding of constitutional court jurisdiction within the democratic process".
} 
como jogadores), ficam em uma situação puramente paradoxal de ter que concordar sobre as regras do jogo, sem abandoná-lo no processo. A única maneira de sair disto é quando as soluções vistas até este nível do jogo e suas regras, já não estão disponíveis de forma geral. Todas as três dimensões podem então constituir uma orientação categórica, na qual já não pode ser burlada, e cuja forma e o equilíbrio podem ser continuamente redefinidos. A abertura procurada por meio deste enfoque não marca uma debilidade na democracia, mas sim delineia seu potencial inerente para o desenvolvimento e a resolução de problemas, e retrata o caráter da democracia como um conceito de limites. Dentro desta definição, os limites das três dimensões (e com isso a quantidade destas normas que deixaram ou que está em vigor), são continuamente redefinidas, sem perder sua identidade.

Uma possível otimização da relação entre as três dimensões da democracia aponta para a extensão e maior desenvolvimento do caráter deliberativo dos procedimentos democráticos. Estes representam a única possibilidade de uma mediação apropriada e diferenciada entre essas dimensões que competem entre si, e ao mesmo tempo são complementares. Enquanto não sejamos capazes de ampliar a discussão, devemos notar que o domínio superior do perfil das três dimensões não podem ser interpretadas linearmente de acordo com o ditado "quanto mais, mais democrático". Ao mesmo tempo, este perfil não deve cair sob um limiar mais baixo. Para sua classificação dentro de uma democracia que funcione bem, não importa em que nível está desenvolvida uma dimensão individual, se todas as três dimensões mostram suas características principais em um nível satisfatório. Se as dimensões individualmente não existem em um nível satisfatório, mas suficiente, falaríamos de uma democracia deficiente. Se as características dos componentes individuais da democracia estão debaixo do limiar não poderíamos falar de uma democracia. Seguindo estas observações, é possível investigar um possível declínio na qualidade democrática. Além do mais, o conceito proposto nos permite ampliar a discussão de um equilíbrio apropriado ao nível de princípios, o qual será realizado na sessão seguinte.

\section{Responsividade - uma base fundamental para a democracia?}

Existem duas razões pelas quais a discussão deve focar na responsividade. Primeiro, no debate público geral, a qualidade da democracia, e com ela, a regressão da democracia é frequentemente vinculada a esta, como comumente o demonstram as queixas sobre os políticos: "eles fazem o que bem entendem" e "eles deveriam escutar mais as pessoas". Segundo, para esta análise estamos considerando uma definição crucial da democracia, a qual deu a direção a pesquisa em Democracia Comparada. A definição a que nos referimos é a de Robert Dahl (1971, p. 2), que define a democracia usando como característica central a responsividade: "I should like to reserve the term "democracy" for a political system, one of 
the characteristics of which is the quality of being completely responsive to all its citizens". Quanto mais forte se observam as preferências dos cidadãos, mais se pode falar de uma democracia. Esta perspectiva se reflete dentro de muitas concepções da democracia e forma um argumento fundamental na defesa da democracia direta (SAWARD, 1994). Como afirma Lipjart (1984, p. 1), "responsividade completa" é o ideal " ao qual os regimes democráticos deveriam aspirar". Da mesma forma, Saward (1994, p. 14) faz deste termo o foco de sua concepção da democracia da seguinte maneira: "a political system is democratic to the extend that, and only to the extent that, it envolves realization of responsive rule". Como se mencionou anteriormente, Diamond e Morlino (2004, p. 30) vêem a responsividade como uma "das oito diferentes dimensões da qualidade da democracia". Crouch (2004) também levanta que a falta de responsividade é uma das principais características da pós-democracia.

Nessas discussões, frequentemente se ignora que a qualidade da democracia revela-se por meio do princípio da responsabilidade. Isto pode entrar em conflito com o princípio de responsividade. Quais são, então, os critérios necessários para resolver o conflito em termos de qualidade democrática? Por outro lado, deveria ser discutido sob quais circunstâncias pode a responsividade (ou os procedimentos relacionados) ser um critério apropriado para determinar a qualidade de uma democracia, e quando não. Acaso um menor nível de responsividade indica sempre uma perda de qualidade democrática ou vice-versa?

\section{Discussão: os limites da responsividade}

Quando podem ou devem procedimentos garantir a responsividade em sua extensão total? As seguintes reservas podem ser mencionadas, ainda que os procedimentos de democracia indireta são mais fortemente afetados do que os do tipo direto:

(1) A primeira restrição ou argumento lógico se estabelece dentro da discussão de eleição coletiva e se concentra nos limites dos procedimentos em si, que produzem resultados diferentes de acordo com o método de comunicação preferido empregado, indicando assim a manipulação das maiorias, como Manfred Schmidt (1995) descreve detalhadamente. Ricker (1980), por exemplo, afirma em sua crítica da regra da maioria que inclusive uma leve manipulação dos procedimentos de tomada de decisão pode ter uma influência duradoura sobre o resultado. Exemplos clássicos da construção técnica dos resultados são os paradoxos de Ostrogorski e o de Condorcet ${ }^{8}$. Com uma perspectiva destes argumentos, Hadenius (1992,

\footnotetext{
${ }^{8}$ De acordo com o paradoxo de Ostrogorski, somente a regra aplicada de tomada de decisões e tipo de voto com respeito às alternativas podem afetar decisivamente a decisão. Assim, as maiorias são criadas artificialmente. Inclusive com o paradoxo de Condorcet, só o procedimento de votação determina os resultados em caso de maiorias cíclicas ou instáveis.
} 
p. 19) deduz que "[...] no complete, reliable reflection of individual preferences is possible. 'The instrument' to measure the opinion [...] always dictates the result to some extent'.

Os procedimentos também podem encontrar mais limitações, já que as preferências dos cidadãos são tão díspares que não podem ser integradas sem cair em contradições e assim nunca poderão ser satisfeitas (ver o Teorema da Impossibilidade de Arrow, 1951). Devido, em parte, às severas divisões sociais, uma grande variedade de temas e conteúdos estão na agenda de tomada de decisões. A impossibilidade de satisfazer todas as necessidades reside não só na estrutura conflitiva de suas demandas, mas também em sua parcial instabilidade. Quando se observa a responsividade, se deve considerar que nem todos os interesses são determinados exogenamente e relativamente estáveis, mas que também são modificados, formados e até criados através do processo político em si. O fator da instabilidade de preferências está bem documentado pelas pesquisas, e as enquetes críticas destacam as possibilidades limitadas para medir as preferências dos cidadãos. Isto é especialmente verdadeiro quando se pergunta por novos assuntos os quais não são suficientemente conhecidos.

O problema de uma programação adequada é ainda maior. Qual deveria ser a data específica para a avaliação da capacidade de resposta? Levando em contra os interesses da maioria no dia de eleições, poderia ser contraproducente se as decisões tomadas neste contexto têm mudando significativamente. O problema também surge quando o contexto de tomada de decisões permanece estável, mas as preferências mudam. Deveriam todas as preferências ser medidas continuamente? Além do fato o qual a participação em tal projeto esgotaria todo o tempo e capacidade dos participantes, a habilidade de planejar decisões políticas - que é necessária para cumprir com a tarefa da responsabilidade - desapareceria.

Além do mais, a perda de responsividade é inerente ao princípio de representação (como também Saward,1994 sublinha com razão). Ofertas em bloco de preferências continuamente se apresentam nas eleições em forma de candidatos ou partidos (SCHARPF, 1970). Encontrar uma oferta análoga é mais uma exceção hipotética no conjunto completo de preferências de um eleitor. Como regra, o partido ou o candidato recebe todos esses votos, os quais por comparação com os de outros mostra a maior compatibilidade com suas próprias preferências. A perda nesta transferência de preferências é ainda maior quanto mais individualmente é estruturada uma sociedade. Porque com a individualização os valores que formam identidades coletivas perdem significado; anteriormente, dentro das classes e ambientes estruturados por clivagens sociais, tais grupos tornaram possível uma transferência de preferências mais claras a esses partidos organizados ao longo destas linhas de conflito (LIPSET e ROKKAN, 1967). Estes grupos de valores vinculantes, os quais foram comuns tanto entre os eleitores e candidatos durante as fases dos partidos de massa, foram acompanhados por conexões para relativamente firmes para orientar preferências dentro de 
campos de políticas específicos. O rompimento de tais estruturas de preferências fortemente homogêneas destaca a necessidade de complementar os procedimentos tradicionais de representação com outras formas de participação, no desenvolvimento da democracia, como os procedimentos plebiscitários, os modelos deliberativos e o estabelecimento da agenda pela sociedade civil. A qualidade desses complementos, os quais poderiam ser melhorados o pelos novos meios de comunicação social, podem ser vistos na sua capacidade de aproveitamento através do argumento de heterogeneidade das preferências individuais, para transformá-los em programas consistentes. As eleições isoladamente têm capacidade limitada para nos informar das verdadeiras preferências do eleitorado (POWELL, 2005).

(2) $\mathrm{O}$ argumento empírico inclui um aspecto a mais, o qual se refere primeiro às qualificações e motivações dos que estão exercendo cargos. As eleições democráticas não podem garantir a seleção de requerentes que sejam capazes, por aptidão ou por disposição, para levar a cabo as funções de seus cargos de forma responsável. Em várias democracias existe uma falta geral de candidatos competentes. Eles não têm as aptidões suficientes nem as habilidades para ocupar seus cargos e/ou principalmente buscam seu próprio benefício, o qual é expresso em certas formas de busca de resultados.

Um segundo aspecto tem que ser adicionado. Com a finalidade de assumir apropriadamente as funções de articulação e integração de interesses, são essenciais estruturas organizacional sólidas. Estas estruturas devem ser capazes de orientar processos de comunicação estruturados. Se os partidos são incapazes de fazê-lo, devido à sua própria fragilidade e falta de estabilidade organizacional, nenhuma contribuição às considerações deliberativas dos processos políticos podem ser esperadas. Tal incapacidade é ilustrada pelos partidos populistas, desinteressados em qualquer forma de intercâmbio através de discussões, e mais ainda na manipulação da opinião pública, abordando ou promovendo unicamente certos temas. Da mesma maneira, os partidos clientelistas dificilmente são capazes de realizar este trabalho, já que seus processos de comunicação interna se orientam de acordo com as lealdades pessoais. Fora a tendência para a instabilidade de padrões organizacionais personalistas, nestes contextos o debate problemático ficará reduzido a meras declarações verbais.

Estes problemas mencionados podem serem reduzidos pela periodicidade das eleições, já que este traz consigo a possibilidade de revisar os erros óbvios nas nomeações e alcançar uma maior responsividade. Esta idéia também segue a Teoria Econômica da Democracia (DOWNS, 1968) em sua resposta de aproximação através de input e output. De acordo com isto, portadores dos mandatos e partidos eleitos buscam realizar suas promessas, a partir das quais foram eleitos, com o fim de assegurar sua reeleição. Por esta razão, através do 
desempenho de governo, as preferências (dos cidadãos "vitoriosos") são em grande parte levadas em conta e assim a responsividade do sistema político é assegurada. Desta forma, a abordagem da resposta nos informa sobre a relativa satisfação dos eleitores; entretanto, não diz nada sobre o enfoque das preferências quanto ao seu conteúdo, e muito pouco sobre as possibilidades de participação e suas limitações e, portanto, muito pouco sobre a qualidade da democracia. Mesmo ditadores podem atender às preferências de seus subordinados.

Um problema adicional surge quando as estruturas do mercado político são distorcidas por estruturas oligopólicas. Este argumento crítico contra o pluralismo foi introduzido no debate e reforçado pelas considerações de Mancur Olson em suas deliberações sobre a lógica da ação coletiva. De acordo com ele, nem todos os interesses têm igual oportunidade de serem articulados e integrados. Não existe uma oferta que garanta todas as preferências existentes. O partido vitorioso só pode representar a oferta que é percebida como a menos "ruim". Os casos mais problemáticos são aqueles em que a responsividade é sistematicamente minada por cartéis de elites nos quais as oportunidades de mudanças são limitadas. A qualidade dos procedimentos em uma democracia em funcionamento sem dúvida permanece sem ser alcançada quanto às decisões políticas - como Offe (1996, p. 146) formula seguindo as discussões de Bobbio e Zolo - se apresentam a si mesmas simplesmente como "um artefato dos cartéis das elites e de estratégias midiáticas" e quando o cidadão é entendido como uma superfície na qual estratégias manipulativas da elite são projetadas.

Determinar a responsividade apropriada também é difícil, já que se refere não somente a orientar as preferências, mas também as estratégias, das quais o seguimento serviria à realização das referidas preferências. Nisto, as preferências de objetivos e de estratégias não devem necessariamente corresponder umas às outras. Em qual caso, no entanto, a responsividade é mais assegurada - quando as estratégias preferidas são aplicadas, mas são infrutíferas ou quando por meio de estratégias não desejadas as metas preferidas são alcançadas? Estas possibilidades fortemente divergentes na interpretação do mesmo fenômeno destacam o problema de vincular diretamente a responsividade com o desempenho da democracia. A pertinência desta pergunta é óbvia considerando o atual debate sobre as respostas certas à crise financeira. Este exemplo também indica a tensão possível entre ambos os princípios. Uma perda de responsividade poderia ser contrabalançada pelo maior grau de responsabilidade na resolução de uma crise.

(3) O argumento da capacidade destaca o problema da implementação. Mesmo se fosse possível encontrar um compromisso exitoso de todos os interesses afetados, não poderia ser garantido que os objetivos previstos seriam alcançados. Não só como o estudo de políticas públicas tem apontado reiteradamente as restrições da implementação (MAYNTZ, 1997). Da mesma forma, o debate sobre a capacidade de condução dos sistemas políticos tem indicado 
problemas no planejamento político. Sem querer difundir um ceticismo generalizado, os déficits de direção não podem ser ignorados (LUHMANN, 1984). Tais dificuldades podem estar na autoridade débil, na forma de trabalho e organização da burocracia, recursos financeiros limitados, na intervenção interruptora de atores interessados, ou em efeitos secundários não intencionais nem calculados. Muitos pontos se relacionam com o tema do governo efetivo, a partir do qual a falta de resposta se deve à limitação da capacidade de governar, frente ao qual o governo só é parcialmente responsável.

No caso de nenhuma responsabilidade não podemos falar de uma perda de responsividade, ainda em caso de resultados pobres. Muitas preferências não podem ser realizadas em curto prazo. E como poderia uma falha na execução ser interpretada devido a um estabelecimento de preferências irreais? Pode o fato de os propósitos utópicos sendo perseguidos ser uma expressão da qualidade democrática insuficiente? Em certo sentido isso seria correto, como poderia se suspeitar de que a discrepância representa o resultado de uma deliberação insuficiente dentro do processo político. Teria de ser julgado de outra forma se um propósito utópico fosse perseguido conscientemente com um a finalidade de estabelecer um símbolo correspondente, o qual em longo prazo possa contribuir com a realização do referido propósito.

Além do mais, o estabelecimento da responsividade por si só não garante a racionalidade das decisões. Uma democracia não pode garantir sempre soluções razoáveis. Entretanto, através de um melhoramento qualitativo nos procedimentos, a racionalidade das decisões pode ser melhorada, como é o tema de discussão dentro do contexto de modelos de democracia deliberativa. De fato, se as democracias são capazes de produzir soluções irracionais, o juízo do desempenho (sócio-econômico) não é apropriado como critério de classificação dos regimes. Regimes autoritários podem considerar úteis as decisões para desenvolvimento de um país. Em certas instâncias, inclusive os regimes autoritários buscam alcançar isto, junto com a fundação ideológica do regime, a geração de outputs promove uma importante forma de melhorar sua legitimidade. Contudo, sua forma de conhecer sistematicamente as preferências da população é impedida, já que esta, por sua parte, tem limitado as possibilidades de articular suas necessidades devido à autoritária limitação da participação. Outro obstáculo no cumprimento das preferências da maioria é que todo governo autocrático busca satisfazer interesses individuais que não são os interesses da maioria (FAUST, 2007).

(4) Depois de expor os limites de comunicação e de realização de preferências, a pergunta permanece em discussão é se a responsividade é sempre desejada no todo e em que medida representa uma característica básica da democracia na realidade. Isto se relaciona com 
um argumento normativo que surge da pergunta sobre se o governo deveria mostrar-se a si mesmo como responsável com relação às preferências sem se importar para quais interesses são expressadas. Pode a responsividade ser desejada quando, com respeito a certos valores, é acompanhada por efeitos políticos negativos (resultados), quando os direitos das minorias são restringidos ou quando o sistema democrático ou o respeito à legalidade são postem em questão? Como podemos ou devemos reagir, quando maiorias fundamentalistas que vão contra a democracia se manifestam dentro da sociedade? Neste dilema, obviamente não existe uma solução satisfatória. A responsividade em relação às preferências situadas fora do consenso democrático básico, assim como sua negação, implica ao menos na suspensão temporal dos procedimentos democráticos. A pergunta (ou o dilema) ilustra que as preferências devem ser julgadas utilizando os limites inerentes dentro do marco da democracia, e que a responsabilidade não pode ser estendida a todas as preferências.

O problema das preferências, que minam a democracia, é incluído por Dahl (1989) na medida em que vincula a formação de preferências com padrões cognitivos, os quais se supõem em grande medida que excluem tais disposições. Para uma expressão apropriada das preferências individuais, ele crê que

[...] each citizen ought to have adequate and equal opportunities for discovering and validating (within the time permitted by the need for a decision) the choice of the matter to be decided that would best serve the citizen's interests. [...] A person's good or interest is whatever that person would choose with the fullest attainable undestanding of the experience resulting from that choice and its most relevant alternatives. (DAHL, 1989, p. 207).

Contudo, estas exigências, estabelecidas pelo critério de "compreensão informada" são tão altas que em sua forma empírica dificilmente poderiam ser eficazes. Entre as condições 'realistas', a exclusão de decisões 'problemáticas' não está assegurada por mais potencial de manipulação (populista) que exista. A responsividade não garante per se um resultado compatível com a democracia. A responsividade como princípio puramente formal não é suficiente para caracterizar a democracia; ademais, a qualificação normativa das preferências desde uma perspectiva da teoria democrática é essencial.

Um princípio de limitação da responsividade é marcado pelo conceito de responsabilidade, o qual considera a responsabilidade daqueles no governo e se orienta para a estabilidade da democracia. A definição de democracia de Przeworski (1988, p. 61) pode ilustrar isto. De acordo com a sua definição, a democracia é uma 'incerteza organizada dentro de supostos básicos fixos'. Para Przeworski et. al. (1996, p. 50) um regime democrático é “a regime in witch governmental offices are filled as a consequence of contested elections. Only 
if the opposition is allowed to compete, win, and assume office is a regime democratic". Consequentemente, três características distinguem um regime democrático, a saber "incerteza ex ante... irreversibilidade ex post... e repetitividade". A característica da repetitividade logicamente exclui a eliminação dos procedimentos democráticos. Em uma democracia, nenhum conteúdo material pode ser definido a priori; e isso se deve à incerteza inerente ao processo democrático de tomada de decisões já que é precisamente este conteúdo o que pode ser confirmado apenas a posteriori, como resultado do procedimento. Entretanto, se a característica de repetitividade é levada a sério, certos resultados podem ser excluídos. Teríamos que excluir aquelas decisões que, por sua vez, minam as bases dos procedimentos escolhidos. Desta forma, o horizonte objetivo da ação democrática, que funciona de acordo com o princípio de responsabilidade, não permanece completamente indefinido ${ }^{9}$. Analisar com seriedade a responsabilidade também ajuda a resolver o problema de Dahl. Um fator institucional - como as cortes supremas - pode ajudar a evitar uma responsividade que viole as normas democráticas. Se ficarmos somente no mundo do controle pessoal de Dahl, nos esperaria um enorme trabalho de educação política.

\section{Conclusão}

Foram considerados quatro tipos de argumentos concernentes à importância da responsividade no conceito de democracia. A lógica do argumento é principalmente convencer e indicar que existem limites óbvios no enfoque da resposta. $\mathrm{O}$ argumento empírico também ressalta aspectos importantes que são incluídos em parte no conceito de Crouch da PósDemocracia. A maioria deles, no entanto, não são inerentes à definição de democracia e podem ser mudados na pesquisa empírica. Isto é parcialmente certo para o argumento da capacidade. Fortes limitações são destacadas pelo argumento normativo, o qual reforça a qualificação dos resultados das políticas vis-à-vis "a compatibilidade normativa" da decisão com valores democráticos. Como um resultado destas considerações, podemos concluir que apesar de seu o indiscutível núcleo democrático, a responsividade de um governo só é adequada de forma limitada como uma expressão da qualidade da democracia. Este caminho, sem incluir o princípio de responsabilidade, se mostra a si mesmo consistentemente como um beco sem saída. Ou para expressar de outra forma, definir a democracia unicamente através da responsividade é tão insatisfatório como ignorá-la. A esperança de Dahl de "responsividade completa" não pode ser garantida, nem da perspectiva da Teoria da Democracia poderia ser

\footnotetext{
${ }^{9}$ Desta forma, uma política razoável não só teria que considerar os interesses dos cidadãos eleitores, mas também deveria incluir os de todas as pessoas afetadas pela decisão. Isto poderia incluir - como o problema da proteção do meio ambiente mostra - nas deliberações às gerações futuras.
} 
sempre útil. A conexão irreflexiva da vontade do eleitor não pode ser um critério decisivo para definir a democracia.

Isto não torna necessário a eliminação deste termo da Teoria da Democracia, mas simplesmente requer a explicação de seus problemas, limites e pré-condições. Também é necessário incluir a idéia básica de que a ação do governo está vinculada aos desejos e necessidades da população, dentro da análise de um governo democrático, e dentro da interpretação reflexiva da perspectiva oferecida aqui. A responsividade pode ser retratada como compatível com a democracia na medida em que os procedimentos democráticos podem se consolidar através da deliberação e ao mesmo tempo existe a certeza do respeito à legalidade. Estas reflexões destacam que medir a qualidade da democracia não deveria depender apenas da responsividade. A responsabilidade também é um indicador da qualidade da democracia e um contrapeso da responsividade. Análises e exaustivas da democracia deveriam incluir as dimensões e princípios principais, enquanto sempre mantenha em mente que a democracia é um conceito limítrofe sensível a potenciais conflitos de objetivos.

Hans-Joachim Lauth é Professor Doutor do Institute of Political Science and Social Research na University of Würzburg. Mantém a Cátedra de Política Comparada.

\section{Referências}

ALEXY, Robert. Die Institutionalisierung der Menschenrechte im demokratischen Verfassungsstaat. In: GOSEPATH, Stefan; LOHMANN, Georg (Hrsg.). Philosophie der Menschenrechte. Frankfurt: Main, 1998. p. 244-264.

ARROW, Kenneth. Social Choice and Individual Values. New Haven: Yale University Press, 1951.

BENZ, Arthur. Föderalismus und Demokratie. Eine Untersuchung zum Zusammenwirken zweier Verfassungsprinzipien. Polis, Hagen, n. 57, p. 1-34, 2003.

BRENNAN, Andrew. Necessary and Sufficient Conditions. Stanford Encyclopedia of philosophy. 2003. Disponível em: <http://plato.stanford.edu/entries/necessary-sufficient/>. Acesso em: 30 set. 2012. 
BÜHLMANN, Marc; MERKEL, Wolfgang; MÜLLER, Lisa; WESSELS, Bernhard. Quality of Democracy. Democracy Barometer for Established Democracies. Working Paper No 10a. NCCR-Democracy. Universität Zürich und WZB, 2008.

CROUCH, Colin. Post Democracy. Cambridge: Polity Press, 2004.

DAHL, Robert A. Polyarchy. Participation and Opposition. New Haven/London: Yale University Press, 1971.

. Democracy and its Critics. New Haven/London: Yale University Press, 1989.

DIAMOND, Larry; MORLINO, Leonardo. The Quality of Democracy. An Overview. Journal of Democracy, Washington, v. 15, n. 4, p. 14-25, oct. 2004.

(eds.). Assessing the Quality of Democracy. Baltimore: John Hopkins University Press, 2005.

DOWNS, Anthony. Ökonomische Theory der Demokratie. Tübingen: Universität Tübingen, 1968.

FAUST, Jörg. Democracy's Dividend: Political Order and Economic Productivity. World Political Science Review, Montreal, v. 3, n. 2, article 2, 2007.

HABERMAS, Jürgen. Die Einbeziehung des Anderen: Studien zur politischen Theorie. Frankfurt/Main, 1996.

HADENIUS, Axel. Democracy and Development. Cambridge: Cambridge University Press, 1992.

HELD, David (ed.). Models of Democracy. Stanford: Stanford University Press, 1987.

HÖFFE, Otfried. Wieviel Politik ist dem Verfassungsgericht erlaubt? Der Staat, v. 38, n. 2, p. 171-193, 1999.

LAUTH, Hans-Joachim. Demokratie und Demokratiemessung. Eine konzeptionelle Grundlegung für den interkulturellen Vergleich. Wiesbaden: VS Verlag, 2004. 
LIJPJART, Arend. Democracies: Patterns of Majoritarian and Consensus Government in Twenty-one Countries. New Haven: Yale University, 1984.

LIPSET, Seymour Martin. Some Social Requisites of Democracy: Economic Development and Political Legitimacy. American Political Science Review, Denton, v. 53, n. 1, p. 69-105, mar. 1959.

LIPSET, Seymour Martin; ROKKAN, Stein (Hrsg.). Party Systems and Voter Alignments. Toronto: The Free Press, 1967.

LUHMANN, Niklas. Soziale Systeme. Grundriß einer allgemeinen Theorie. Frankfurt/Main: Suhrkamp, 1984.

MAYNTZ, Renate. Politische Steuerung und gesellschaftliche Steuerungsprobleme. In: MEISTER, Christian. Soziale Dynamik und politische Steuerung. Frankfurt: Grin, 1997. p. 186-208.

MERKEL, Wolfgang; PUHLE, Hans-Jürgen; CROISSANT, Aurel; EICHER, Claudia; THIERY, Peter. Defekte Demokratien. Bd. 1: Theorie, Opladen, 2003.

MUNO, Wolfgang. Demokratie und Entwicklung, Mainz (Institut für Politikwissenschaft, Abt. politische Auslandsstudien und Entwicklungspolitik, Dokumente und Materialien Nr. 29, 2001.

O’DONNELL, Guillermo; VARGAS CULLELL, Jorge; IAZZETTA, Osvaldo (eds.). The Quality of Democracy. South Bend: University of Notre Dame Press, 2004.

OFFE, Claus. Bewährungsproben - Über einige Beweislasten bei der Verteidigung der liberalen Demokratie. In: WEIDENFELD, Werner (ed.). Demokratie am Wendepunkt. Berlin: Siedler Verlag, 1996. p. 141-157.

POWELL, G. Bingham. The Chain of Responsiveness. In: DIAMOND, Larry; MORLINO, Leonardo (eds.). Assessing the Quality of democracy. Baltimore: John Hopkins University Press, 2005. p. 62-76. 
PRZEWORSKI, Adam. Democracy as a Contingent Outcome of Conflicts. In: ELSTER, Jon; SLAGSTAD, Rume (eds.). Constitutionalism and Democracy. Cambridge: Cambridge University Press, 1988. p. 59-80.

PRZEWORSKI, Adam et. al. What makes Democracies Endure. Journal of Democracy, Washington, v. 7, n. 1, p. 39-56, jan. 1996.

REISINGER, William M. Choices Facing the Builders of a Liberal Democracy. In: GREY, Robert. Democratic Theory and Post-Communist Change. New Jersey: Prentice Hall, 1997. p. 24-51.

RIKER, William H. A Reply to Ordeshook and Rae. American Political Science Review, Denton, v. 74, n. 2, p. 456-458, jun. 1980.

SARTORI, Giovanni. Concept Misformation in Comparative Politics. American Political Science Review, Denton, v. 64, n. 4, p. 1033-1053, dec. 1970.

SAWARD, Michael. Democratic Theory and Indices of Democratization. In: BEETHAM, David (ed.). Defining and Measuring Democracy. London: SAGE, 1994. p. 6-24.

SCHARPF, Fritz W. Demokratietheorie zwischen Utopie und Anpassung. Konstanz: Konstanzer Universitätsreden, 1970.

SCHMIDT, Manfred G. Demokratietheorien. Eine Einführung, Opladen (2006, dritte überarbeitete und erweiterte Auflage, Wiesbaden, 1995.

SCHMITTER, Philippe C. The Ambiguous Virtues of Accountability. In: DIAMOND, Larry; MORLINO, Leonardo (eds.). Assessing the Quality of democracy. Baltimore: John Hopkins University Press, 2005. p. 18-31.

ZIPPELIUS, Reinhold. Allgemeine Staatslehre. München, 11te Auflage (erste Auflage 1969), 1991.

Texto recebido em 30/08/2012.

Aprovado em 17/12/2012. 